\title{
Physical self-esteem of wheelchair basketball players
}

\author{
Samir Qasim*, Yaser Telfah, and Yazan Haddad \\ Faculty of Physical Education, Yarmouk University, Irbid, Jordan
}

Copyright: (C) 2018 S. Qasim et al. This is an open access article licensed under the Creative Commons Attribution License (https://creativecommons.org/licenses/by/4.0/).

\begin{abstract}
Background: Physical self has been considered as one of the most important factors that impact global self-esteem. Similarly to global self-esteem, physical self is now widely accepted as a multidimensional construct which contains more specific perceptions across various domains. However, limited research examined physical self of athletes with physical disabilities. Objective: This study, aimed to investigate physical self-esteem of wheelchair basketball players and to explore correlations among various physical domains and physical self-esteem. Methods: Forty one basketball players who participated in West Asian Wheelchair Basketball Championship for the clubs completed Physical Self-Description Questionnaire (PSDQ). It is a 70-item questionnaire that measures physical self-perception across nine domains: Health, Coordination, Activity, Body Fat, Sport Competence, Appearance, Strength, Flexibility, and Endurance. Additionally, this questionnaire assesses each of Physical Self-Esteem and Global Self-Esteem. Pearson correlation coefficient was used to measure these correlations. Results: Study results showed that the participants reported positive perceptions across all physical domains as means ranged from 3.86 to 4.93 (out of 6). The highest mean was 4.93 for global self-esteem followed by physical appearance and body fat (mean 4.75 and 4.70 respectively), whereas physical activity had the lowest mean of 3.86. Furthermore, all domains were significantly correlated to the physical self-esteem. Importantly, coordination accounted for $85.9 \%$ and $54.4 \%$ of the variance in physical selfesteem and physical activity respectively. Conclusion: This study supports a multidimensional construct of physical self-esteem, suggesting that PSDQ may be applied on the wheelchair basketball players in the Middle East countries.
\end{abstract}

Keywords: multidimensional construct, physical self, physical disability

\section{Introduction}

People have been seeking success in different life domains in order to experience high self-esteem and avoid low self-esteem (Crocker, Moeller, \& Aleah, 2010). Self-esteem has been identified as one of the main factors for human functioning and performance that is related to general well-being and mental health (Buckworth, Dishman, O'Connor, \& Tomporowski, 2013; Lindwall \& Asci, 2014). Furthermore, high self-esteem is positively associated with personal, mental and social health (Torres, Fernandez, \& Maceira, 1995). High self-esteem is also linked to increased academic achievement, improved health, productive behaviour (Daglas-Pelish, 2006), happiness and life satisfaction (Harter, 1993; Lindwall \& Asci, 2014). Conversely, low self-esteem may be a precipitating

\footnotetext{
* Address for correspondence: Samir Qasim, Department of Sport Sciences, Faculty of Physical Education, Yarmouk University, Defense Street, Swimming pool Building (AA3), 21163 Irbid, Jordan. E-mail: samir.qasim@yu.edu.jo
}

factor of unhealthy behaviour (Hayes \& Fors, 1990). Low self-esteem has also been identified as a possible risk factor for depression (Harter, 1993; Peden, Hall, Rayens, \& Beebe, 2000) and can result in the development of behavioural disorders (Egan \& Perry, 1998; Mann, Hosman, Schaalma, \& De Vries, 2004).

However, as self-esteem is a multidimensional hierarchical construct (Boyd \& Hrycaiko, 1997; Marsh, 1990; Marsh, Craven, \& Martin, 2006; Sabiston, Whitehead, \& Eklund, 2012), it is influenced by people's perceptions across different domains. One of these important domains is physical self-esteem (Fox \& Corbin, 1989) that can be described as a multidimensional hierarchical subjective perception and affective evaluation of people's various physical traits. The physical self has been considered as one of the most important factors correlated to global selfesteem throughout all ages (Fox, 2000). Moreover, Harter (2012) reported that perceptions of physical appearance, which is known to be the physical selfesteem domain (Marsh, Richards, Johnson, Roche, 
\& Tremayne, 1994; Messer \& Harter, 1986), best predicted self-esteem for people with and without disabilities. Also, the physical self may mediate the influence of exercise on health related physical activity and fitness (Marsh \& Peart, 1988) which means that because of the exercise programs athletes improve their physical self-esteem and consequently develop their physical outcomes.

The research show that people with disabilities are less physically active than their able-bodied peers (Dishman, Heath, \& Washburn, 2004). People with disability face either personal or social challenges which limit their intensive participation in physical activity (school activities, sport clubs, exercises). For instance, Buffart, Westendorp, van den Berg-Emons, Stam, and Roebroeck (2009) conducted a focus group interview with young adults $(N=16)$ with physical disabilities in the Netherlands and found that barriers related to attitude and motivation, lack of energy, limited physical facilities, and lack of information were the main barriers for their limited physical activity. As a consequent, people with disability have lower physical activity habitual levels and lower perceived fitness compared to their peers without disability (Dishman et al., 2004). By contrast, people with disability boost their self-esteem when participating in physical activities and have higher self-esteem compared to inactive individuals with disability (Campbell \& Jones, 1994; Hutzler \& Bar-Eli, 1993). This finding has been confirmed on wheelchair basketball players as well (Ferreira \& Fox, 2008). Authors found that wheelchair basketball players have higher physical self-esteem and physical domains (except body attractiveness) than sedentary individuals without disability.

However, limited research examined physical self of athletes with disability. This becomes particularly important considering that physical self in athletes with physical disability is differently structured than physical self of individuals without disability (Ferreira \& Fox, 2008). Shapiro and Martin (2010) predicted reported physical activity behaviour and global selfesteem using a multidimensional physical self-concept model. They found a number of significant correlations among global self-esteem and physical activity behaviours and physical self-domains. For example, global physical self-concept, strength, endurance, sport competence predicted reported physical activity behaviour and global self-esteem using a multidimensional physical self-concept model. They found a number of significant correlations among global self-esteem and physical activity behaviours and physical self-domains. For example, global physical self-concept, strength, endurance, and flexibility were related to self-esteem while only two physical domains, endurance and sport competence, were associated with reported physical activity. The current study aimed to investigate the levels of physical self-esteem domains, physical selfesteem, and global self-esteem of wheelchair basketball players in Middle Eastern countries. We also sought to explore correlations among physical self-esteem, various physical domains and global self-esteem. Finally, we aimed to predict each of physical activity, physical self-esteem, and global self-esteem of athletes with physical disability.

\section{Methods}

\section{Participants}

After obtaining approval from the internal committee at the faculty of physical education at Yarmouk University for conducting this study, basketball coaches of four teams that participated in the West Asian Championship were contacted. In total 41 information and consent sheets were distributed to participants of four wheelchair basketball teams. All players agreed to be involved in the study. All players were male (age $=31 \pm 6.6$ years) playing for their national teams (Jordan, Palestine, and Oman). Participants had cerebral palsy $(n=18)$, spina bifida $(n=13)$, leg length difference $(n=6)$, and four participants whose disability was not reported.

\section{Procedures}

For the purposes of this study we used physical selfdescription questionnaire (PSDQ) developed by Marsh et al. (1994). According to Sabiston et al. (2012) PSDQ is one of the best measures for physical self-perception that has been widely used in the literature. It has shown high internal reliability (Marsh, Asci, \& Tomas, 2002) and median test retest correlation (Marsh, Papaioannou, \& Theodorakis, 2006). Furthermore, Shapiro and Martin (2010) used the PSDQ with athletes with physical disability. PSDQ is a 70-item questionnaire that measures physical self-perception across nine domains: Health, Coordination, Activity, Body Fat, Sport Competence, Appearance, Strength, Flexibility, and Endurance in addition to Physical Self-Esteem and Global Self-Esteem. Each item, regardless physical domain, was rated using a six-point Likert Scale in which higher score reflex better perception of the certain domain or physical self-esteem. The questionnaires were distributed a day before competitions began in the hotel hall, after breakfast, and returned on the same day. This was done to avoid possible impact of the games results on self-perception. Moreover, the authors gave standard verbal instructions about the questionnaire and encouraged the participants to answer honestly. As PSDQ contains 70 items, participants had a whole day to complete 
the questionnaire. After dinner, the coaches returned to the authors all questionnaires. Importantly, due to the participants' limited knowledge on English language, Arabic translation of PSDQ was distributed to all participants (Mouissi, Lazaar, Ninot, \& Turki, 2010).

\section{Data analyses}

Descriptive analysis and coefficient alphas (Cronbach, 1951) were calculated for all PSDQ domains. The normality of data distribution was confirmed using Kolmogorov-Smirnov test. Pearson correlation coefficient was applied to measure correlations between physical self-esteem and each physical self domain using SPSS (Version 20; IBM, Armonk, NY, USA). Moreover, multiple regression analyses were used to predict physical activity and physical self-esteem. However, only those variables that have been identified as significantly correlated to physical activity and physical self-esteem were selected as predictors $(p<.05)$.

\section{Results}

Internal consistency for most of the PSDQ domains were considered relatively high $(\alpha=.79-.93)$. However, coefficient alphas of health domain showed poor internal consistency $(\alpha=.29)$ and therefore it was excluded from further analysis (Table 1).

Table 1 also shows that the participants reported relatively high perceptions across all physical domains as means ranged from 3.86 to 4.93 (out of 6). The highest mean was 4.93 for global self-esteem followed by physical appearance and body fat (mean 4.75 and 4.70 respectively), whereas physical activity had the lowest mean of 3.86 .

Furthermore, all physical domains in addition to global self-esteem were significantly correlated to the physical self-esteem (Table 2). Similarly, physical domains, except body fat, and global self-esteem were significantly correlated to physical activity.

Table 1

Basic description of the physical domains, global self-esteem, and physical self-esteem $(N=41)$

\begin{tabular}{lccccc}
\hline Domain & Mean & $S D$ & Minimum & Maximum & $\alpha$ \\
\hline Health & 4.11 & 0.557 & 3 & 5 & .29 \\
Coordination & 4.24 & 1.346 & 1 & 6 & .92 \\
Physical activity & 3.86 & 1.128 & 2 & 6 & .79 \\
Body fat & 4.70 & 1.280 & 2 & 6 & .91 \\
Sports competence & 4.30 & 1.229 & 2 & 6 & .88 \\
Physical appearance & 4.75 & 1.044 & 2 & 6 & .85 \\
Strength & 4.30 & 1.079 & 2 & 6 & .81 \\
Flexibility & 4.39 & 1.229 & 1 & 6 & .90 \\
Endurance & 4.31 & 1.264 & 1 & 6 & .90 \\
Global self-esteem & 4.93 & 1.081 & 2 & 6 & .93 \\
Physical self-esteem & 4.41 & 0.953 & 2 & 6 & .91 \\
\hline
\end{tabular}

Table 2

Pearson correlation between physical self-esteem, physical activity, all physical domains and global self-esteem $(N=41)$

\begin{tabular}{lccccc}
\hline & \multicolumn{2}{c}{ Physical activity } & & \multicolumn{2}{c}{ Physical self-esteem } \\
\cline { 2 - 3 } \cline { 5 - 6 } Domain & $r$ & $p$ & & $r$ & $p$ \\
\hline Coordination & .737 & $<.001$ & & .934 & $<.001$ \\
Physical activity & & & & .723 & $<.001$ \\
Body fat & .248 & .118 & & .602 & $<.001$ \\
Sports competence & .712 & $<.001$ & & .919 & $<.001$ \\
Physical appearance & .489 & .001 & & .871 & $<.001$ \\
Strength & .563 & $<.001$ & & .880 & $<.001$ \\
Flexibility & .727 & $<.001$ & & .948 & $<.001$ \\
Endurance & .670 & $<.001$ & & .871 & $<.001$ \\
Global self-esteem & .471 & .002 & & .913 & $<.001$ \\
\hline
\end{tabular}


Multiple regression analyses to predict physical activity and physical self-esteem were calculated based only on those domains that have been identified as significantly correlated to them (Table 3 and 4 respectively). Therefore, we included all these independent variables within one block for predicting each of physical self-esteem and physical activity. Study results showed that coordination accounted for $85.9 \%$ and $54.4 \%$ of the variance in physical self-esteem and physical activity respectively.

\section{Discussion}

The first aim of this study was to investigate physical selfesteem levels of wheelchair basketball players. Considering that this study was conducted on elite athletes, who involve in international sport events, it is not surprising to find that their physical self-esteem and physical self domains were relatively high. Participants in our study achieved higher scores in each of physical self-esteem, sport competence, physical appearance, and strength compared to the scores of athletes from the previous study (Ferreira \& Fox, 2008) whereas other physical domains used in the current study are not within Physical Self-Perception Profile structure that was used in their study. We suggest that athletes from our study were physically prepared as they were supposed to play in the regional championship which could have had impact on their physical self. This means that that they felt physically prepared for the competitions. This finding has been supported by Cocquyt and Sigmund (2011) who found a positive relationship between sport participation and increased self-perception among people with physical disabilities. Scarpa (2011) found that adolescence and young adults with physical disabilities who regularly exercise achieved higher scores in global self-esteem and physical self-esteem than their peers who did not exercise regularly.

Moreover, a previous study showed that international wheelchair athletes have higher self-esteem than the athletes who participate only in the national competitions (Campbell \& Jones, 1994).

Table 3

Multiple regression results predicting physical activity

\begin{tabular}{lccccc}
\hline & $\begin{array}{c}\text { Multiple } \\
\text { correlation } \\
\text { coefficient }(R)\end{array}$ & $\begin{array}{c}\text { Coefficient of } \\
\text { determination } \\
\left(R^{2}\right)\end{array}$ & Adjusted $R^{2}$ & \multicolumn{1}{c}{$F$} & $p$ \\
\hline Variable & .737 & .544 & .532 & 46.47 & $<.001$ \\
Spoordination & .712 & .507 & .495 & 40.14 & $<.001$ \\
Physical appearance & .489 & .239 & .220 & 12.25 & .001 \\
Strength & .563 & .317 & .300 & 18.14 & $<.001$ \\
Flexibility & .323 & .104 & .081 & 4.54 & .040 \\
Endurance & .670 & .449 & .435 & 31.82 & $<.001$ \\
Physical self-esteem & .729 & .531 & .519 & 44.23 & $<.001$ \\
Global self-esteem & .471 & .222 & .202 & 11.11 & .002 \\
\hline
\end{tabular}

Table 4

Multiple regression results predicting physical self-esteem

\begin{tabular}{lccrrr}
\hline Multiple & $\begin{array}{c}\text { coefficient of } \\
\text { correlation } \\
\text { coefficient }(R)\end{array}$ & $\begin{array}{c}\text { Cetermination } \\
\left(R^{2}\right)\end{array}$ & Adjusted $R^{2}$ & \multicolumn{1}{c}{$F$} & \multicolumn{1}{c}{$p$} \\
\hline Cariable & .927 & .859 & .855 & 236.98 & $<.001$ \\
Physical activity & .729 & .531 & .519 & 44.23 & $<.001$ \\
Body fat & .496 & .246 & .227 & 12.72 & .001 \\
Sports competence & .913 & .833 & .829 & 195.18 & $<.001$ \\
Physical appearance & .824 & .678 & .670 & 82.21 & $<.001$ \\
Strength & .866 & .751 & .744 & 117.36 & $<.001$ \\
Flexibility & .507 & .257 & .238 & 13.48 & .001 \\
Endurance & .882 & .779 & .773 & 137.17 & $<.001$ \\
Global self-esteem & .881 & .776 & .771 & 135.47 & $<.001$ \\
\hline
\end{tabular}


In addition, the current finding rejects an assumption that people with physical disabilities have low selfperception regarding their physical competence, body appearance, body image and body esteem (Rumsey \& Harcourt, 2004; Taleporos \& McCabe, 2001). We consider that this disagreement is associated with the fact that participants from our study are regularly physical active athletes continuously emphasizing physical skills and liberated body (Taub, Blinde, \& Greer, 1999). They further argued that such attitude helps in stigma management which is particularly important taking into account that disadvantaged and stigmatized social position is associated with lower self-esteem among people with physical disability compared to those without disability (Tam, 1998). Moreover, a positive relationship between regular participation in physical activities and physical appearance among lower limb amputees was found (Wetterhahn, Hanson, \& Levy, 2002). It is worth noting that the lowest mean was found for physical activity similarly as in the previous research (Shapiro \& Martin, 2010). In our study physical appearance had the highest mean followed by body fat whereas Shapiro and Martin found the highest mean for body fat. We believe that this result is also similar because both physical appearance and body fat are related to physical outlook. In contrast to the previous studies in which people with physical disabilities reported low endurance (Martin, 2007; Shapiro \& Martin, 2010), participants from the current study perceive themselves good at endurance levels.

Another purpose of this study was to explore correlations among various physical domains and physical self-esteem. Our results showed that all physical domains are significantly related to physical self-esteem. This finding supports a hierarchical construct of physical self, proposed by Fox and Corbin (1989). Previous research found that such construct of physical self is also visible in people with physical disabilities (Uchida, Hashimoto, \& Lutz, 2005). Such as in the previous study (Shapiro \& Martin, 2010) a positive relationship between physical self-esteem and global self-esteem in athletes with physical disabilities was found.

The multiple regression results provide important indications about the importance of physical domains that predict physical self-esteem and physical activity. Although coordination accounted for the most variance $(85.9 \%)$, another physical domains such as sports competence, strength, endurance as well as global self-esteem were also important. In agreement with the previous study (Shapiro \& Martin, 2010) participants expressing strong perceptions of physical self-esteem and above mentioned domains reported favourable global self-esteem compared to those reporting weaker self-perception in the physical domains. The findings in regard to predicting physical activity also show coordination for the most variance (54.4\%) but less compared to the physical self-esteem. This result is not surprising considering that coordination, such as physical activity, is physical self-esteem subdomain. Furthermore, all participants were athletes and therefore perceptions of coordination, sports competence, and endurance were expected to be important in predicting physical activity.

A major limitation that should be considered when analysing the current results is the relatively small sample size although Shapiro and Martin (2010) applied their study on 37 athletes. Moreover, this study did not explore whether the onset of disability influenced participants' physical self-esteem as Sherrill (2004) reported that people with congenital physical disability have higher self-esteem compared to persons who acquired their physical disability after birth. She also believes that gender may play an important role regarding some physical domains particularly physical appearance. However, we did not include female participants in this study, although females with physical disability place more importance on physical appearance (Appleton et al., 1994), because few female athletes participate in wheelchair basketball teams in the Middle East countries. We noticed that there seems to be no studies exploring a particular physical domain and therefore we would suggest that researchers focus on this issue as a hierarchical model of physical selfesteem on people with disability has been confirmed (Uchida et al., 2005).

\section{Conclusion}

In summary, the current findings demonstrate that basketball wheelchair players from Middle Eastern countries have relatively high physical self-esteem and physical self domains. A hierarchical construct of physical self-esteem has been supported in this study.

\section{Conflict of interest}

There were no conflicts of interest.

\section{References}

Appleton, P. L., Minchom, P. E., Ellis, N. C., Elliott, C. E., Böll, V., \& Jones, P. (1994). The self-concept of young people with spina bifida: A population-based study. Developmental Medicine \& Child Neurology, 36, 198-215.

Boyd, K., \& Hrycaiko, D. (1997). The effect of a physical activity intervention package on the self-esteem of 
pre-adolescent and adolescent females. Adolescence, 32, 693-708.

Buckworth, J., Dishman, R., O’Connor, P., \& Tomporowski, P. (2013). Exercise psychology (2nd ed.). Champaign, IL: Human Kinetics.

Buffart, L. M., Westendorp, T., van den Berg-Emons, R. J., Stam, H. J., \& Roebroeck, M. E. (2009). Perceived barriers to and facilitators of physical activity in young adults with childhood-onset physical disabilities. Journal of Rehabilitation Medicine, 41, 881-885.

Campbell, E., \& Jones, G. (1994). Psychological well-being in wheelchair sport participants and nonparticipants. Adapted Physical Activity Quarterly, 11, 404-415.

Cocquyt, M., \& Sigmund, E. (2011). The impact of competition in physical activity and sport on the self-perception of individuals with physical disabilities. Acta Universitatis Palackianae Olomucensis. Gymnica, 41(1), 43-50.

Crocker, J., Moeller, S., \& Aleah, B. (2010). The costly pursuit of self-esteem: Implications for self-regulation. In R. H. Hoyle (Ed.), Handbook of personality and self-regulation (pp. 403-430). Oxford, United Kingdom: Blackwell Publishing.

Cronbach, L. J. (1951). Coefficient alpha and the internal structure of tests. Psychometrika, 16, 297-334.

Daglas-Pelish, P. (2006). Effects of a self-esteem intervention program on school-age children. Pediatric Nursing, 32, 341-348.

Dishman, R. K., Heath, G. W., \& Washburn, R. A. (2004). Physical activity epidemiology. Champaign, IL: Human Kinetics.

Egan, S. K., \& Perry, D. G. (1998). Does low self-regard invite victimization? Developmental Psychology, 34, 299-309.

Ferreira, J. P., \& Fox, K. R. (2008). Physical self-perceptions and self-esteem in male basketball players with and without disability: A preliminary analysis using the physical self-perception profile. European Journal of Adapted Physical Activity, 1, 35-49.

Fox, K. R. (2000). The effects of exercise on self-perceptions and self-esteem. In S. J. H. Biddle, K. R. Fox, \& S. H. Boutcher (Eds.), Physical activity and psychological wellbeing (pp. 88-117). London, United Kingdom: Routledge.

Fox, K. R., \& Corbin, C. B. (1989). The physical self-perception profile: Devlopment and preliminary validation. Journal of Sport and Exercise Psychology, 11, 408-430.

Harter, S. (1993). Causes and consequences of low selfesteem in children and adolescents. In R. Baumeister (Ed.), Self-esteem: The puzzle of low self-regard (pp. 87-116). New York, NY: Plenum.

Harter, S. (2012). The construction of the self: Developmental and sociocultural foundations (2nd ed.). New York, NY: Guilford Publications.

Hayes, D. M., \& Fors, S. W. (1990). Self-esteem and health instruction: Challenges for curriculum development. Journal of School Health, 60, 208-211.

Hutzler, Y., \& Bar-Eli, M. (1993). Psychological benefits of sports for disabled people: A review. Scandinavian Journal of Medicine \& Science in Sports, 3, 217-228.
Lindwall, M., \& Asci, H. F. (2014). Physical activity and self-esteem. In A. Clow \& S. Edmunds (Eds.), Physical activity and mental health (pp. 83-105). Champaign, IL: Human Kinetics.

Mann, M. M., Hosman, C. M. H., Schaalma, H. P., \& De Vries, N. K. (2004). Self-esteem in a broad-spectrum approach for mental health promotion. Health Education Research, 19, 357-372.

Marsh, H. W. (1990). A multidimensional, hierarchical model of self-concept: Theoretical and empirical justification. Educational Psychology Review, 2, 77-172.

Marsh, H. W., Asci, F. H., \& Tomas, I. M. (2002). Multitrait-multimethod analyses of two physical self-concept instruments: A cross-cultural perspective. Journal of Sport and Exercise Psychology, 24, 99-119.

Marsh, H. W., Craven, R. G., \& Martin, A. (2006). What is the nature od self-esteem? Unidimensional and multidimensional perspectives. In M. H. Kernis (Ed.), Selfesteem issues and answers: A sourcebook of current perspectives (pp. 16-24). New York, NY: Psychology Press.

Marsh, H. W., Papaioannou, A., \& Theodorakis, Y. (2006). Causal ordering of physical self-concept and exercise behavior: Reciprocal effects model and the influence of physical education teachers. Health Psychology, 25, 316-328.

Marsh, H. W., \& Peart, N. D. (1988). Competitive and cooperative physical fitness training programs for girls: Effects on physical fitness and multidimensional self-concepts. Journal of Sport and Exercise Psychology, 10, 390-407.

Marsh, H. W., Richards, G. E., Johnson, S., Roche, L., \& Tremayne, P. (1994). Physical self-description questionnaire: Psychometric properties and a multitrait-multimethod analysis of relations to existing instruments. Journal of Sport and Exercise Psychology, 16, 270-305.

Martin, J. J. (2007). Physical activity and physical self-concept of individuals with disabilities: An exploratory study. Journal of Human Movement Studies, 52, 37-48.

Messer, B., \& Harter, S. (1986). Manual for the adult selfperception profile. Denver, CO: University of Denver.

Mouissi, F., Lazaar, S., Ninot, G., \& Turki, R. (2010). Alnuskha Aljazaeriyeh Lmeqas Wasf Althat Albadaniyeh [Algerian version of PSDQ]. Alacademiyeh Lldarasat Alensaniyeh Wa Alejtimaiyeh, 4, 57-63.

Peden, A. R., Hall, L. A., Rayens, M. K., \& Beebe, L. (2000). Negative thinking mediates the effect of self-esteem on depressive symptoms in college women. Nursing Research, 49, 201-207.

Rumsey, N., \& Harcourt, D. (2004). Body image and disfigurement: Issues and interventions. Body Image, 1, 83-97.

Sabiston, C., Whitehead, J. R., \& Eklund, R. C. (2012). Exercise and self-perception constructs. In G. Tenenbaum, R. C. Eklund, \& A. Kamata (Eds.), Measurement in sport and exercise psychology (pp. 227-238). Champaign, IL: Human Kinetics.

Scarpa, S. (2011). Physical self-concept and self-esteem in adolescents and young adults with and without physical disability: The role of sports participation. European Journal of Adapted Physical Activity, 4, 38-53. 
Shapiro, D. R., \& Martin, J. J. (2010). Multidimensional physical selfconcept of athletes with physical disabilities. Adapted Physical Activity Quarterly, 27, 294-307.

Sherrill, C. (2004). Adapted physical activity, recreation, and sport: Crossdisciplinary and lifespan (6th ed.). Dubuque, IA: The McGraw-Hill Companies.

Taleporos, G., \& McCabe, M. P. (2001). The impact of physical disability on body esteem. Sexuality and Disability, 19, 293-308.

Tam, S.-F. (1998). Comparing the self-concepts of persons with and without physical disabilities. Journal of Psychology, 132, 78-86.

Taub, D. E., Blinde, E. M., \& Greer, K. R. (1999). Stigma management through participation in sport and physical activity: Experiences of male college students with physical disabilities. Human Relations, 52, 1469-1484.

Torres, R., Fernandez, F., \& Maceira, D. (1995). Selfesteem and value of health as correlates of adolescent health behavior. Adolescence, 30, 403-412.

Uchida, W., Hashimoto, K., \& Lutz, R. (2005). Examination of the hierarchical self-esteem model in adults with physical disability. Perceptual and Motor Skills, 100(3 suppl), 1161-1170.

Wetterhahn, K. A., Hanson, C., \& Levy, C. E. (2002). Effect of participation in physical activity on body image of amputees. American Journal of Physical Medicine \& Rehabilitation, 81, 194-201. 